\title{
THE GENUS PRIOTOMIS IN ARGENTINA (HYMENOPTERA, ICHNEUMONIDAE)*
}

\author{
By Charles C. Porter \\ Department of Biological Sciences, Fordham University \\ Bronx, N.Y. 10458
}

The genus Priotomis (Townes, 1969, p. 292) was placed by its author in the subtribe Lymeonina of the ichneumonid tribe Mesostenini. While data provided by a study of the new species t:eated in this article do not controvert that placement, it is well to emphasize that Priotomis shows a number of singularly aberrant characters unparalleled among other genera of its subtribe. For example, the presence of a series of teeth on the dorsal valve of the ovipositor tip recalls the Baryceratina rather than the Lymeonina, whereas the specialized, twisted mandibular apex is not found in any other mesostenine genus.

Priotomis was described from a unique female collected in the wet subtropical forest of Santa Catarina State in southern Brasil. Now, however, another specimen has come to light, from the invernally deciduous Chaco Forest of northwest Argentina, and this form, while agreeing perfectly with Townes' diagnosis of Priotomis, differs in so many respects from its Brazilian congener that it must be recognized as a separate species.

\section{Genus Priotomis Townes}

Priotomis Townes, 1969. Mem. Amer. Ent. Inst., 12: 292-293.

Type: Priotomis rana Townes. Original designation.

Length of fore-wing: $6.0-7.8 \mathrm{~mm}$. Body: relatively robust. Eyes: somewhat protruding. Clypeus: uniformly flat or with the basal 0.6 weakly convex and the apical 0.4 flat; apical margin straight or a little convex, thin, without a tooth or median irregularity. Mandible: with its apex twisted in such a manner that the lower tooth is located almost directly beneath the upper tooth. Pronotum: epomia absent; dorsal margin not swollen. Mesoscutum: short, mat, with rather dense setae; notauli absent. Mesopleuron: sternaulus weak or well defined, but not extending more than half the distance to middle coxa. Mesosternum: median part of postpectal carina absent. Wing venation: areolet small, square, apically open; nervulus antefurcal; mediella strongly arched; axillus relatively close to the hind margin of the wing and parallel to it. Propodeum: short, its basal trans-

*Manuscript received by the editor June 18, 1972 
verse groove shallow and rather narrow; spiracle subcircular; basal trans-carina well defined but becoming comparatively weaker medially; apical trans-carina lacking. First gastric tergite: without longitudinal carinae; spiracle at apical $0.30-0.35$. Second tergite: with comparatively dense setae. Ovipositor: sheathed portion $0.23-0.25$ as long as the hind tibia; compressed; nodus weak and low; dorsal valve on tip with a series of 6-9 small teeth.

\section{Key to the Species of Priotomis}

I. Second gastric tergite smooth and shining; head with profuse white markings; mesoscutum with a pair of longitudinal white lines; propodeum with a basal white blotch

I. P. golbachi n. sp.

Second gastric tergite mat; head completely black; mesoscutum without white lines; propodeum without a basal white blotch, with pale subapical areas only

2. P. rana Townes.

\section{Priotomis golbachi n.sp}

Figure I

Holotype: (female) ARgentina (Salta: Urundel, January 3I, 1950, R. Golbach). (Tucumán).

Female: Color: antenna black with a white dorsal band that begins at the apex of 5th flagellomere and extends to the base of 12th; flagellomeres 6-10 each also with a little white near the base ventrally; apex of pedicel and base of first flagellomere tinged with dark brown, and apical I/3 of flagellum ventrally stained with gray.

Head and mesosoma black with the following white markings: pair of large dorso-lateral blotches on clypeus; central blotch on front; wide orbital band, which below extends broadly across malar space but which above is interrupted over about the upper $1 / 3$ of the external orbit; broad band on all but hind angle of anterior margin of pronotum; large blotch medially on dorso-lateral margin of pronotum; tegulae; pair of longitudinal lines on mesoscutum; scutellum, except near apex; large blotch on subalarum; large, irregular, oblique blotch that covers much of lower $2 / 3$ of mesopleuron between the prepectal carina and the lower hind corner; upper $2 / 3$ of hind margin of mesopleuron; a pair of extensive, very much browntinged blotches on mesosternum near bases of coxae; large blotch covering most of upper division of metapleuron; oval medio-basal blotch on propodeum; and a pair of very large and irregular posterolateral areas situated partly on propodeum and partly on dorsal region of lower division of metapleuron; some cephalic and mesosomatic 


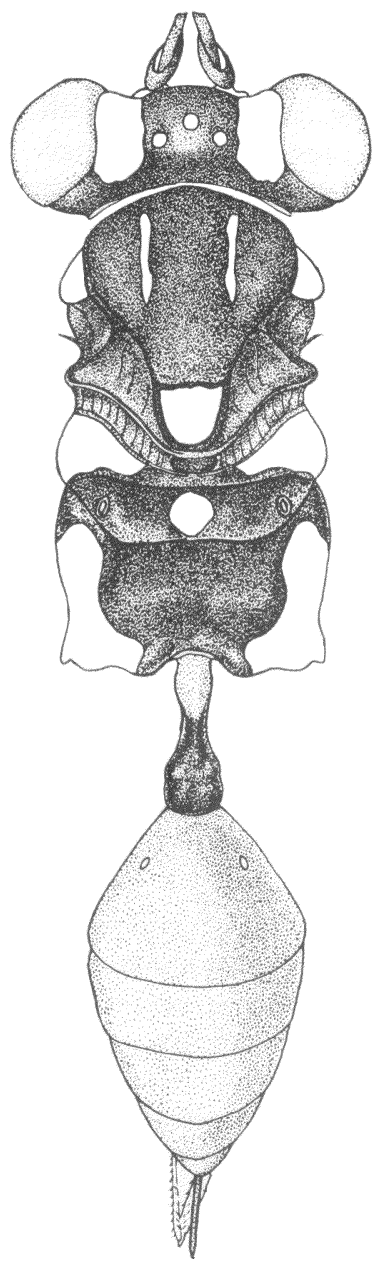

Figure 1. Priotomis golbachi n. sp. Dorsal view of female holotype, showing color pattern of body. 
margins and sutures, including apical half of clypeus, tinged with brown.

Wings hyaline, very slightly darkened apicad.

Petiole whitish below and whitish with much brown staining above; postpetiole black; rest of gaster orange.

Fore-leg with coxa black with much brown staining and with an extensive dorso-lateral white blotch; trochanter whitish with duskybrown staining posteriorly; trochantellus whitish; femur whitish with an extensive dusky-brown area on much of posterior face except near base and apex; tibia whitish; tarsomeres I-2 whitish and 3-5 black; mid-legs with coxa, trochanters, and femur orange, except for a longitudinal dusky-brown area situated postero-dorsally on subapical half of femur; tibia yellowish; tarsomeres I-2 yellowish and 3-5 black with a little yellowish near base of 3 ; hind-legs with coxa, trochanters, and femur orange, except that femur has a large black dorso-lateral area, which begins very narrowly a little before the middle and extends, becoming progressively wider, as far as the apex; tibia yellow with base narrowly black; tarsomeres I-3 yellow and 4-5 black.

Length of fore-wing: $7.8 \mathrm{~mm}$.

Flagellum: long, rather stout, the basal 2/3 distinctly compressed but the apical $1 / 3$ tending to cylindric; first segment 3.8 as long as deep at apex. Clypeus: uniformly flat, apical margin straight. Malar space: I.2 as long as basal width of mandible. Temple: 0.2 as long as eye in dorsal view; strongly and directly receding. Occipital carina: interrupted above on about the median half.

Wing venation: upper part of nervellus 0.7 as long as lower part.

Postpetiole: $\mathrm{I} .3$ as wide apically as long from spiracle to apex. Second gastric tergite: smooth and polished with very weak microreticulation and with numerous small, superficial punctures that in general are separated by distinctly more than their diameters and which emit short setae for the most part as long as or only a little shorter than their interspaces.

Ovipositor: sheathed portion 0.25 as long as hind-tibia.

MALE: unknown.

Collections: The holotype has been deposited in the collection of the Instituto Miguel Lillo, S.M. de Tucumán, R. Argentina.

SPECIFIC NAME: This species is named in honor of Sr. Rodolfo Golbach, whose tireless fieldwork of several decades has done much to make the collection at Tucumán the finest in Latin America.

Habitat Notes: Sr. Golbach reports that he obtained the unique female of this species in a small patch of woods near the station of 
the Ferrocarril General Belgrano at Urundel in Salta Province. The vegetation at Urundel is the so-called Selva Chaqueña, a distinctive type of subtropical deciduous forest, which in northwest $\mathrm{Ar}$ gentina north of Ledesma forms a relatively narrow band of transition between the dry Chaco Scrub on the east and the much wetter Selva Tucumano-Boliviana on the west at the base of the mountains.

AcKNowledgements: It is my pleasure to thank Dr. Jose Antonio Haedo Rossi, Director of the Fundación Miguel Lillo, for providing working space and equipment during the course of this study.

Srta. Alicia E. Sandoval of the Fundación Miguel Lillo inked the figure used to illustrate this paper from a pencil sketch supplied by the author.

Townes, H. K.

REFERENCE

1969. Genera of Ichneumonidae, Part 2. Gelinae. Mem. Amer. Ent. Inst. 12. 

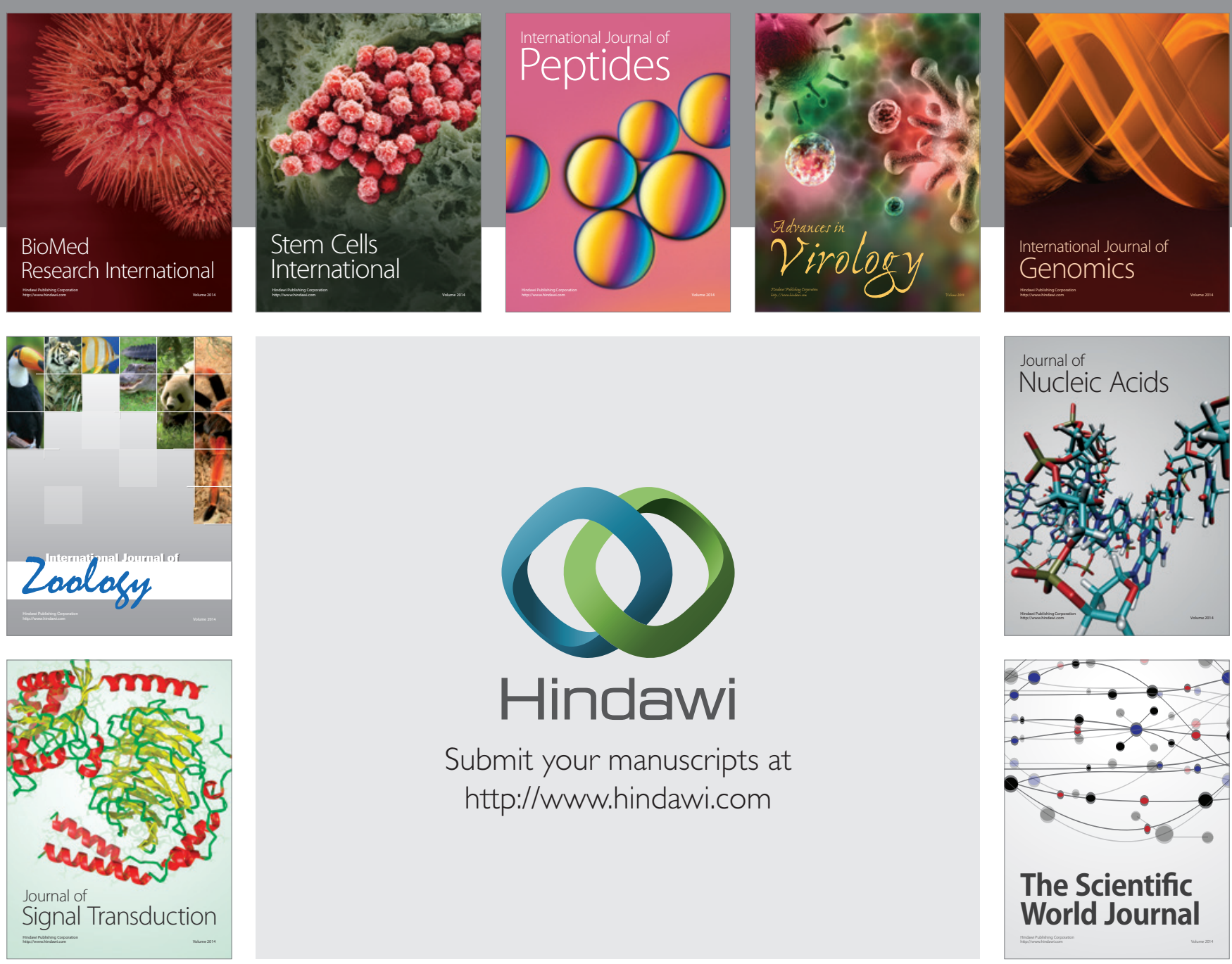

Submit your manuscripts at

http://www.hindawi.com
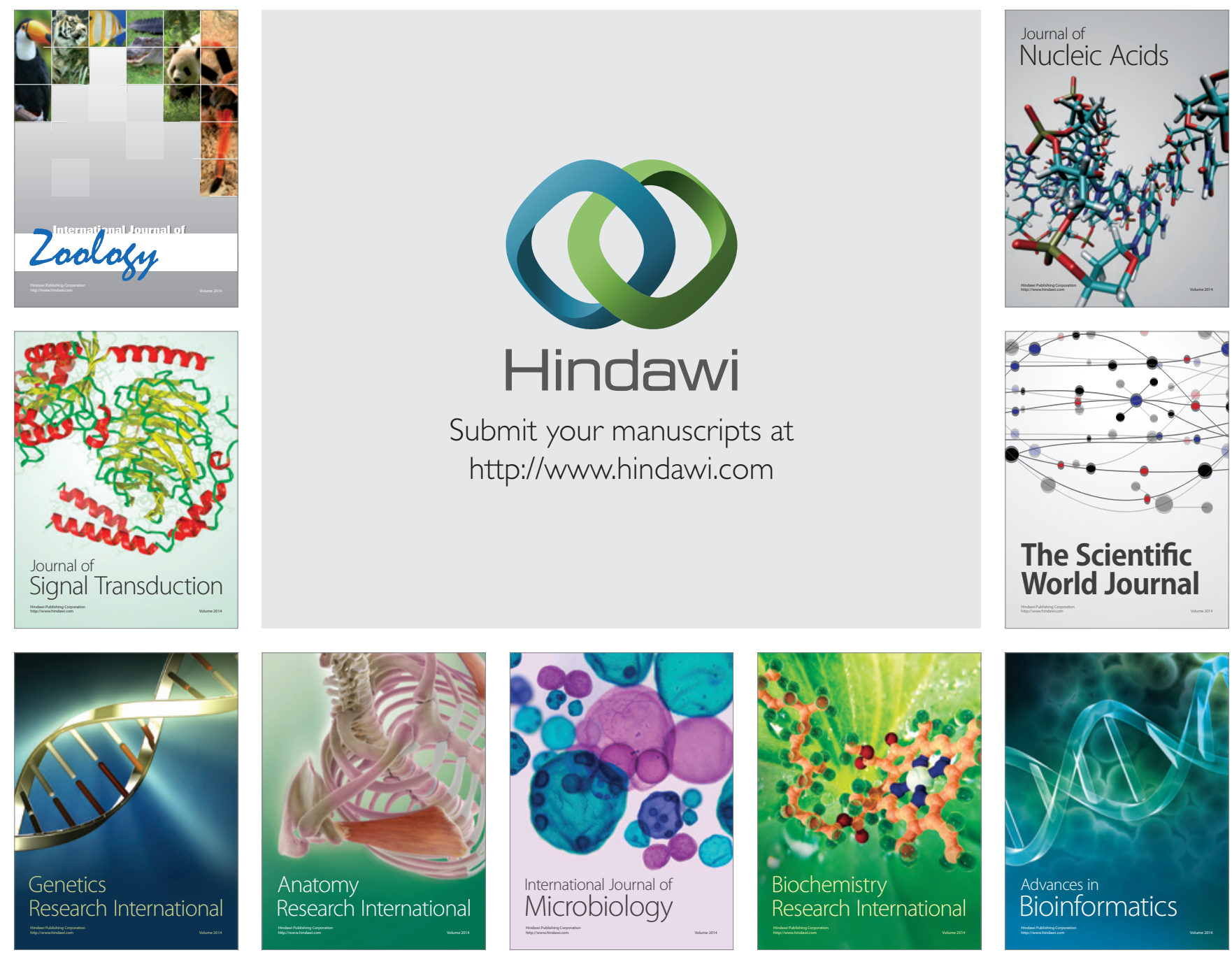

The Scientific World Journal
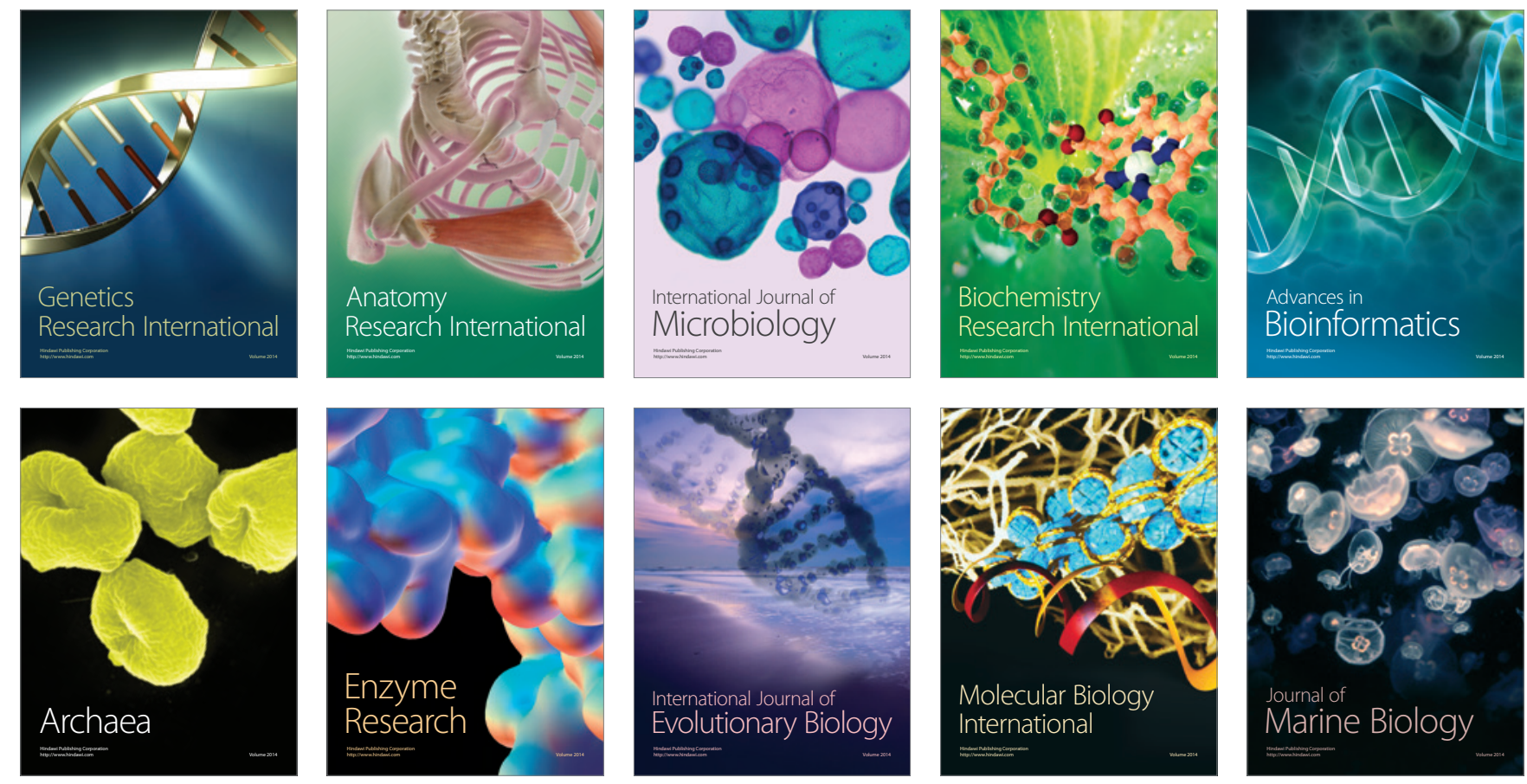